\title{
SOIL MOISTURE SENSOR TEST WITH MISSISSIPPI DELTA SOILS
}

\author{
R. Sui, H. C. Pringle, E. M. Barnes
}

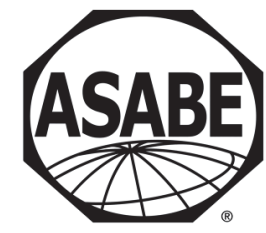

\begin{abstract}
One of the methods for irrigation scheduling is to use sensors to measure the soil moisture level in the plant root zone and apply water if there is a water shortage for the plants. The measurement accuracy and reliability of the soil moisture sensors are critical for sensor-based irrigation management. This study evaluated the measurement accuracy and repeatability of the EC-5 and 5TM soil volumetric water content (SVWC) sensors, the MPS-2 and 200SS soil water potential (SWP) sensors, and the 200TS soil temperature sensor. Six $183 \mathrm{~cm} \times 183 \mathrm{~cm} \times 71 \mathrm{~cm}$ wooden compartments were built inside a greenhouse, and each compartment was filled with one type of soil from the Mississippi Delta. A total of 66 sensors with 18 data loggers were installed in the soil compartments to measure SVWC, SWP, and soil temperature. Soil samples were periodically collected from the compartments to determine SVWC using the gravimetric method. SVWC measured by the sensors was compared with that determined by the gravimetric method. The SVWC readings from the sensors had a linear regression relationship with the gravimetric SVWC $\left(r^{2}=0.82\right)$. This relationship was used to calibrate the sensor readings. The SVWC and SWP sensors could detect the general trend of soil moisture changes. However, their measurements varied significantly among the sensors. To obtain accurate absolute soil moisture measurements, the sensors require individual and soil-specific calibration. The 5TM, MPS-2, and 200TS sensors performed well in soil temperature measurement tests. Individual temperature readings from these sensors were very close to the mean of all sensor readings.
\end{abstract}

Keywords. Irrigation, Sensors, Soil types, Soil water content, Soil water potential.

I rrigation scheduling determines the time and amount of water to apply. Irrigation scheduling methods may be classified into three main categories: weather-based methods, soil moisture-based methods, and plant-based methods. Weather-based methods schedule irrigation based on the amount of water lost by plant evapotranspiration (ET) and the amount of effective rainfall and irrigation water entering the plant root zone. Soil-based methods measure soil moisture or water potential levels in the plant root zone and apply water if there is a water shortage for the plants. Plantbased methods directly detect plant responses to water stress and initialize irrigation as the plants indicate suffering from water stress.

Soil moisture sensors have been widely used to measure

\footnotetext{
cc) (1) $\Theta$ The authors have paid for open access for this article. This work is licensed under a Creative Commons AttributionNonCommercial-NoDerivatives 4.0 International License https:/creative commons.org/licenses/by-nc-nd/4.0/

Submitted for review in April 2018 as manuscript number ITSC 12886; approved for publication by the Information Technology, Sensors, \& Control Systems Community of ASABE in December 2018.

Mention of company or trade names is for description only and does not imply endorsement by the USDA. The USDA is an equal opportunity provider and employer.

The authors are Ruixiu Sui, Research Agricultural Engineer, USDAARS Crop Production Systems Research Unit, Stoneville, Mississippi; Horace C. Pringle, Associate Agricultural Engineer, Delta Research and Extension Center, Mississippi State University, Stoneville, Mississippi; Edward M. Barnes, Senior Director, Cotton Incorporated, Cary, North Carolina. Corresponding author: Ruixiu Sui, USDA-ARS Crop Production Systems Research Unit, 141 Experiment Station Road, P.O. Box 350, Stoneville, MS 38776, USA; phone: 662-686-5382; e-mail: ruixiu.sui@ars.usda.gov.
}

soil moisture status and determine supplementary water requirements by crops. Various types of sensing devices have been developed and made commercially available for water management applications in recent years. Evaluations have shown that each type of sensing device has its advantages and shortcomings in terms of accuracy, reliability, and cost (Basinger et al., 2003; Chanzy et al., 1998; Evett and Parkin, 2005; Seyfried and Murdock, 2004; Yao et al., 2004). The neutron probe has been shown to be a reliable tool for determining soil water content. However, its use of a radioactive source requires special licensing and training for operation and has restricted its application in recent years. Meanwhile, electromagnetic (EM) sensors, such as electrical capacitance and resistance type sensors, and time-domain reflectometry (TDR) devices have been rapidly developed and widely adopted for soil water measurement (Dukes and Scholberg, 2004; Fares and Alva, 2000; Miranda et al., 2005; Seyfried and Murdock, 2001; Vellidis et al., 2008). Yoder et al. (1997) tested 23 soil water sensors representing eight sensor types, including neutron probe, electrical capacitance sensors, electrical resistance sensors, TDR devices, and heat dissipation sensors with carefully controlled soil water contents. Measurement errors of soil volumetric water content (SVWC) were determined for each sensor. The results indicated that the capacitance sensors had the best performance in the study. Leib et al. (2003) evaluated soil moisture sensors of several different brands and types under identical operating conditions in the field for three years. They found that most sensors were able to follow the general trends of soil water or potential changes during the growing season, but actual measured values varied significantly between sensors and calibrated neutron 
probe measurements. They suggested that a soil specific calibration of each sensor was necessary to obtain high accuracy in the measurements. Evett et al. (2006) compared several EM sensors with a neutron moisture meter in measuring the water content of three soils. They found that all EM sensing devices under test were sensitive to soil temperature differences. Similar to the suggestion by Leib et al. (2003), Evett et al. (2006) recommended that all of the EM sensing devices would require separate calibrations for different soil horizons. Vaz et al. (2013) evaluated the factory-supplied calibration relationships of eight EM soil moisture sensors with seven soils from Arizona and tested the influence of the soil properties on the sensor's SVWC measurements. They found that the manufacturer-provided calibration relationships performed well in general, but some inconsistences were observed. Mittelbach et al. (2012) compared the performances of four types of soil moisture sensors in SVWC measurement with a clay loam soil in Switzerland. Three of these sensors were non-TDR sensors, including 10HS (Decagon Devices, Pullman, Wash.), CS616 (Campbell Scientific, Logan, Utah), SISOMOP (SMG University of Karlsruhe, Germany), and the fourth sensors was a TDR sensor (TRIME-IT/EZ, IMKO GmbH, Ettlingen, Germany). Using the respective calibration functions provided by the manufacturers, Mittelbach et al. (2012) concluded that none of the tested nonTDR sensors could satisfactorily capture the actual SVWC measured by the TDR sensor. The root mean square difference (RMSD) of SVWC for the non-TDR sensors compared to the TDR sensor was as high as $0.3 \mathrm{~m}^{3} \mathrm{~m}^{-3}$. In their study, Mittelbach et al. (2012) used SVWC measurement by the TDR sensor as a reference in comparing the measurements by the non-TDR sensors to that of the TDR sensor, instead of comparing all the sensor-measured SVWC values to the SVWC determined using the gravimetric method. In general, previous research has indicated that EM sensors are inexpensive, easy to install and maintain, and able to provide reliable information for irrigation scheduling and control. However, the sensors must be well-calibrated under specific operating conditions, including soil type and temperature.

One of the most popular methods for irrigation scheduling is to measure soil moisture levels in the plant root zone. Soil moisture content can be determined directly using manual gravimetric soil sampling by weighing and drying a soil sample. The gravimetric method is simple. However, it is also time-consuming and expensive because frequent measurements are required. Soil moisture sensors can measure soil moisture content indirectly. Various types of soil moisture sensors have been developed and made commercially available. The soil moisture sensors used in irrigation management include the EC-5 and 5TM SVWC sensors (Decagon Devices, Pullman, Wash.) and the 200SS (Irrometer, Riverside, Cal.) and MPS-2 (Decagon Devices, Pullman, Wash.) water potential sensors.

The Mississippi Delta is one of the major crop production regions in the U.S. In this region, the acreage of irrigated land has increased rapidly in recent years. The producers have come to use soil moisture sensors for irrigation management. Soil physical properties in the Mississippi Delta can vary significantly within a single field, from excessively drained loamy sands to poorly drained clays (Cox et al., 2006; Thomasson et al., 2001).
The objective of this study was to evaluate soil moisture sensors with various types of Mississippi Delta soils to understand how these sensors perform with these soils.

\section{Materials ANd Methods}

\section{SENSOR INSTALLATION}

Six $183 \mathrm{~cm} \times 183 \mathrm{~cm} \times 71 \mathrm{~cm}$ compartments were built in a greenhouse. Six soil types with different physical properties from the Mississippi Delta around Stoneville, Mississippi, were collected, and one type of soil (top soil) was filled in each soil compartment (fig. 1). The compartments were constructed on a concrete foundation. The four sides of the compartments were made of $10 \mathrm{~cm} \times 10 \mathrm{~cm} \times 183 \mathrm{~cm}$ wood blocks so that water was able to drain freely from the compartments through the gaps between the blocks. Water was applied with a sprinkler installed over the compartments to saturate the soils in the compartments. This process was repeated four times to allow the soils to settle before sensor installation. The six soil types were Bosket very fine sandy loam (BVFSL), Sharkey clay (SC), Dundee silty clay (DSC), Dundee very fine sandy loam (DVFSL), Dundee silty clay loam (DSCL), and Tunica clay (TC). The physical properties of the soils were analyzed at the soil test lab of Mississippi State University (table 1).

A total of 66 soil moisture and temperature sensors were tested for measuring SVWC, soil water potential (SWP), and soil temperature, including:

- Eighteen EC-5 SVWC sensors.

- Six 5TM SVWC sensors.

- Eighteen MPS-2 SWP sensors.

- Eighteen 200SS SWP sensors.

- Six 200TS temperature sensors.

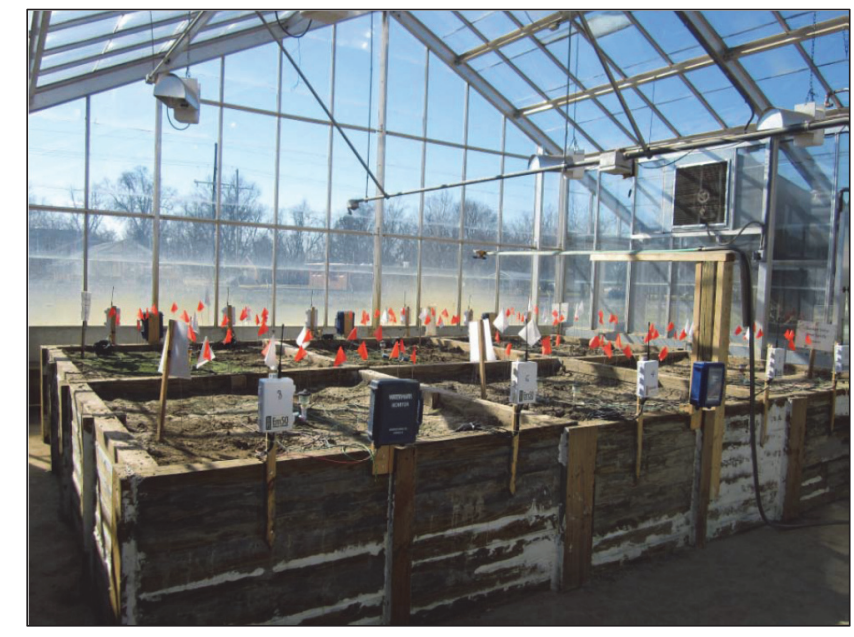

Figure 1. Soil compartments with sensors and data loggers installed.

Table 1. Physical properties of soils used in the sensor test.

\begin{tabular}{cccccc}
\hline Soil & $\begin{array}{c}\text { Clay } \\
(\%)\end{array}$ & $\begin{array}{c}\text { Silt } \\
(\%)\end{array}$ & $\begin{array}{c}\text { Sand } \\
(\%)\end{array}$ & Texture & $\begin{array}{c}\text { Bulk Density } \\
\left(\mathrm{g} \mathrm{cm}^{-3}\right)\end{array}$ \\
\hline BVFSL & 2.5 & 42 & 55.5 & Sandy loam & 1.38 \\
SC & 23.75 & 67.75 & 8.5 & Silt loam & 1.26 \\
DSC & 8.75 & 54.5 & 36.75 & Silt loam & 1.27 \\
DVFSL & 8.75 & 67.5 & 23.75 & Silt loam & 1.36 \\
DSCL & 10 & 72.5 & 17.5 & Silt loam & 1.33 \\
TC & 21.25 & 69.5 & 9.25 & Silt loam & 1.28 \\
\hline
\end{tabular}


The EC-5, 5TM, and MPS-2 sensors were products of Decagon Devices (Pullman, Wash.), while the 200SS and 200TS sensors were manufactured by the Irrometer Company (Riverside, Cal.). These sensors are low-cost and have been widely used by researchers and producers in the Mississippi Delta region.

The EC-5 sensors determine soil SVWC by measuring the dielectric constant of the soil using capacitance-based techniques. A pair of electrodes in the EC-5 sensor forms a capacitor with the soil as the dielectric. The capacitor is connected to an oscillator to form a tuned circuit running at a certain frequency. The capacitance depends on the dielectric permittivity of the soil. Soil moisture can be related to the dielectric permittivity of the soil, and changes in soil moisture can be measured by detecting changes in the dielectric permittivity of the soil through the tuned circuit (Susha Lekshmi S.U. et al., 2014). The EC-5 operates at a frequency of $70 \mathrm{MHz}$ with a measurement volume of about $0.2 \mathrm{~L}$. It measures SVWC in a range of $0 \%$ to $100 \%$ at temperatures ranging from $-40^{\circ} \mathrm{C}$ to $60^{\circ} \mathrm{C}$. The manufacturer reported that the measurement accuracy using generic calibration is $\pm 0.03 \mathrm{~m}^{3} \mathrm{~m}^{-3}$ with mineral soils that have solution EC of $<8 \mathrm{dS} \mathrm{m}^{-1}$ (Decagon, 2010b). The EC-5 consists of two prongs of $5 \mathrm{~cm}$ length. For installation, the sensor can be pushed directly into undisturbed soil.

The operating principle of the 5TM sensor is similar to that of the EC-5, which uses an oscillator running at $70 \mathrm{MHz}$ to determine the SVWC by measuring the soil dielectric permittivity. The 5TM sensor also measures temperature using an onboard thermistor. Its measurement ranges are $0 \%$ to $100 \%$ for SVWC and $-40^{\circ} \mathrm{C}$ to $+50^{\circ} \mathrm{C}$ for temperature. The manufacturer-provided accuracy is $\pm 0.03 \mathrm{~m}^{3} \mathrm{~m}^{-3}$ for SVWC measurement with generic calibration and $\pm 1^{\circ} \mathrm{C}$ for temperature measurement. The dimensions of the $5 \mathrm{TM}$ are $10 \mathrm{~cm}$ $(\mathrm{L}) \times 3.2 \mathrm{~cm}(\mathrm{~W}) \times 0.7 \mathrm{~cm}(\mathrm{D})$. The sensor consists of three prongs of $5.2 \mathrm{~cm}$ length, which allows a measurement volume of about $700 \mathrm{~mL}$ (Decagon, 2010a).

The MPS-2 sensor is a dielectric water potential sensor. Along with measuring soil temperature, the MPS-2 determines the water potential by measuring the dielectric permittivity of a ceramic disc at a frequency of $70 \mathrm{MHz}$. A surfacemounted thermistor underneath the sensor overmold is used to measure the temperature. The dimensions of the sensor are $9.6 \mathrm{~cm}(\mathrm{~L}) \times 3.5 \mathrm{~cm}(\mathrm{~W}) \times 1.5 \mathrm{~cm}(\mathrm{D})$, and the sensor's sensing disc is $3.2 \mathrm{~cm}$ in diameter. The measurement range of the MPS- 2 is -10 to $-100,000 \mathrm{kPa}$. The manufacturer-provided accuracy is $\pm(25 \%$ of reading $+2 \mathrm{kPa})$ over the range of -9 to $-100 \mathrm{kPa}$. Its temperature measurement range is $40^{\circ} \mathrm{C}$ to $60^{\circ} \mathrm{C}$ with an accuracy of $\pm 1^{\circ} \mathrm{C}$ (Decagon, 2017).

The Watermark 200SS sensor is an electrical resistance sensor for determining soil water potential. The sensor consists of a pair of electrodes embedded in a granular matrix. Because the electrical resistance between the electrodes is related to soil moisture content, the soil water potential can be determined by measuring the electrical resistance (Irrometer, 2018). The sensor is $22 \mathrm{~mm}$ in diameter and $83 \mathrm{~mm}$ in length. The measurement range is 0 to $-239 \mathrm{kPa}$. Because readings from the $200 \mathrm{SS}$ can be affected by soil temperature

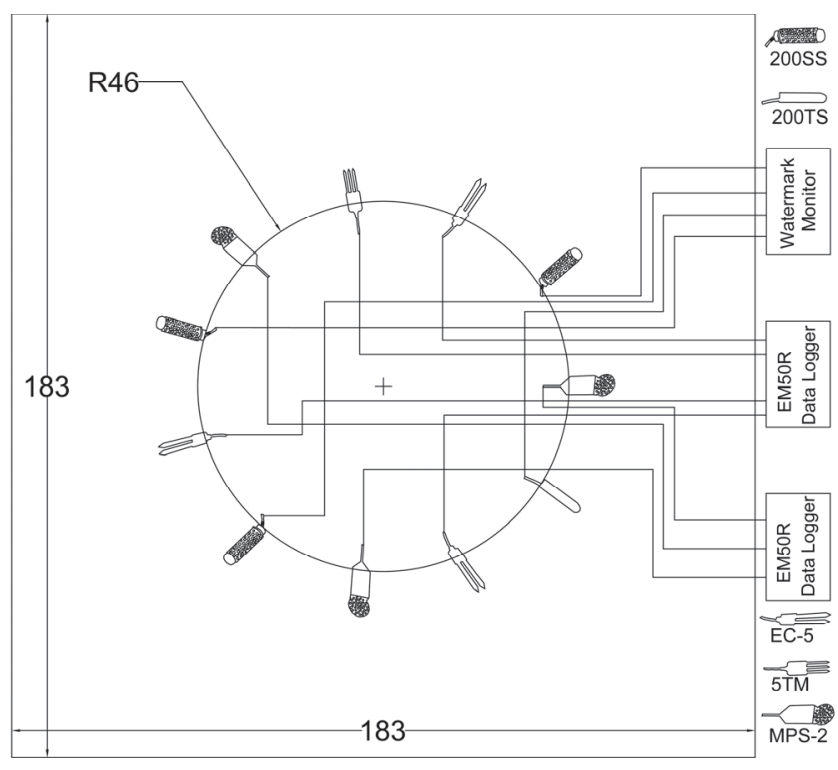

Figure 2. Sensor layout in each compartment (dimensions are cm).

(Thomason and Armstrong, 1987), the 200SS requires temperature compensation for the accurate measurement. A 200TS temperature sensor (Irrometer, Riverside, Cal.) was used to measure the temperature around the 200SS for temperature compensation.

Three EC-5 sensors, three MPS-2 sensors, one 5TM sensor, three 200SS sensors, and one 200TS sensor were installed in each soil compartment. Figure 2 shows the layout of the sensors in each soil compartment. A hole with a diameter of $46 \mathrm{~cm}$ and $38 \mathrm{~cm}$ deep was excavated in the center of each soil compartment for sensor installation. The sensors were installed at a depth of $30.5 \mathrm{~cm}$ around the perimeter of the hole with a center-to-center spacing of about $12.7 \mathrm{~cm}$ between the sensors. The installation was performed according to the instructions provided by each sensor's manufacturer. After all sensors were installed, the hole was refilled with the same soil that had been removed to create the hole, and water was applied to saturate the soil. The water application was repeated three times to resettle the soil.

\section{Data Collection}

Data collection was conducted from February 9 to May 8, 2013. Twelve Decagon data loggers (EM50R, Decagon Devices, Pullman, Wash.) were used to collect data from the EC-5, MPS-2, and 5TM sensors. Six Watermark monitors (900M, Irrometer, Riverside, Cal.) were used to record the data measured by the 200SS and 200TS sensors. The default calibration for "mineral soil" was selected for the Decagon data loggers. A soil temperature sensor was connected to channel 1 of the Watermark monitors for temperature compensation of the soil water potential measurements. The data logging devices were set to automatically collect data from the sensors at a time interval of one hour.

Five cycles of soil sample collection were conducted during the three-month test. Between the cycles, water was applied and the soil was allowed to dry to a desired moisture content before taking samples. In each cycle, three locations were randomly selected in each compartment for soil sampling. Two soil samples were taken at a depth of 27.3 to 
$33.7 \mathrm{~cm}$ in each location to represent the soil at the depth of $30.5 \mathrm{~cm}$ at which soil moisture was measured using the sensors. The soil sample size was $5.4 \mathrm{~cm}$ in diameter and $3.0 \mathrm{~cm}$ in length. After being collected from the compartments, the soil samples were immediately weighed using a balance for wet weight and then oven-dried at $110^{\circ} \mathrm{C}$ until completely dry. The dried samples were then weighed for dry mass weight. Soil bulk density was determined by dividing the sample dry weight by the sample volume (table 1). Volumetric water content $(\theta)$ of the soil samples was determined using equation 1 :

$$
\theta=\frac{V_{l}}{V_{t}}=\frac{\left(W_{w}-W_{d}\right)}{V_{t} \rho_{w}}
$$

where $V_{l}$ is the volume of water, $V_{t}$ is the total volume of the sample, $W_{w}$ is the wet weight of the sample, $W_{d}$ is the dry weight of the sample, and $\rho_{w}$ is the water density.

\section{DATA ANALYSIS}

Soil moisture, soil water potential, and soil temperature of the six soil types were continuously monitored and recorded for three months. All data collected during the threemonth test were downloaded from the data logging devices and processed for calibration and evaluation of the sensors. For each sensor, the sensor readings from 7:30 a.m. to $12: 30$ p.m. (one reading per hour) were averaged to represent the mean measurements for that day. The volumetric water contents determined using the oven-dried method, as described above, were compared with those measured by the EC-5 and 5TM sensors at the time when the oven-dried samples were taken. Regression relationships between the readings of the EC-5 and 5TM sensors and the oven-dried SVWC were established and used to calibrate those sensor measurements. ANOVA was performed with SAS software (SAS Institute Inc., Cary, N.C.) to evaluate the differences in SVWC, SWP, and soil temperature measurements by the sensors.

\section{RESULTS AND DISCUSSION \\ SOIL VOLUMETRIC WATER CONTENT}

A linear regression relationship between the oven-dried SVWC and the SVWC readings measured by the EC- 5 and 5TM sensors $\left(\mathrm{r}^{2}=0.82\right)$ is shown in figure 3 . Each point in the graph represents the average of the sensor-measured SVWC (EC-5 and 5TM) and the average of the oven-dried SVWC for the respective sampling time and soil type. The reason for using the EC-5 and 5TM sensor readings together for the sensor-measured SVWC was that the EC-5 and 5TM sensors are the same type of sensor from the same manufacturer. This regression relationship could be used to correct the sensor readings for accurate SVWC measurement in the various types of Mississippi Delta soils. Using the Decagon "mineral soil" calibration, the sensors obviously overestimated the SVWC. The correlation between the oven-dried SVWC and the sensor readings $(y=0.6508 x+1.7612)$ was then used to calibrate the sensor readings. Figure 4 shows a comparison of the oven-dried SVWC with the calibrated sensor-measured SVWC for the five soil sampling cycles. The average SVWC and the sensor prediction errors across sampling cycles are given in table 2 . The sensor prediction error, defined as predicted minus observed percent volumetric water content, varied from $-8.6 \%$ to $11.8 \%$ depending on the soil type. The minimum prediction error was $2.7 \%$ with the DSC soil, while the maximum error was $11.8 \%$ with the DSCL soil.

In general, the sensor-measured SVWC followed the trend in soil moisture changes for all types of soils during the three-month test, but the SVWC values determined by individual sensors varied. The mean SVWC measured by the EC-5 and 5TM sensors are given in table 3. ANOVA revealed that the SVWC values measured by the EC- 5 \#2 and \#3 sensors in the BVFSL and TC soils were not significantly different. However, the rest of the measurements by each EC-5 sensor within the same soil type varied significantly. The SVWC measured by the 5TM sensors was significantly

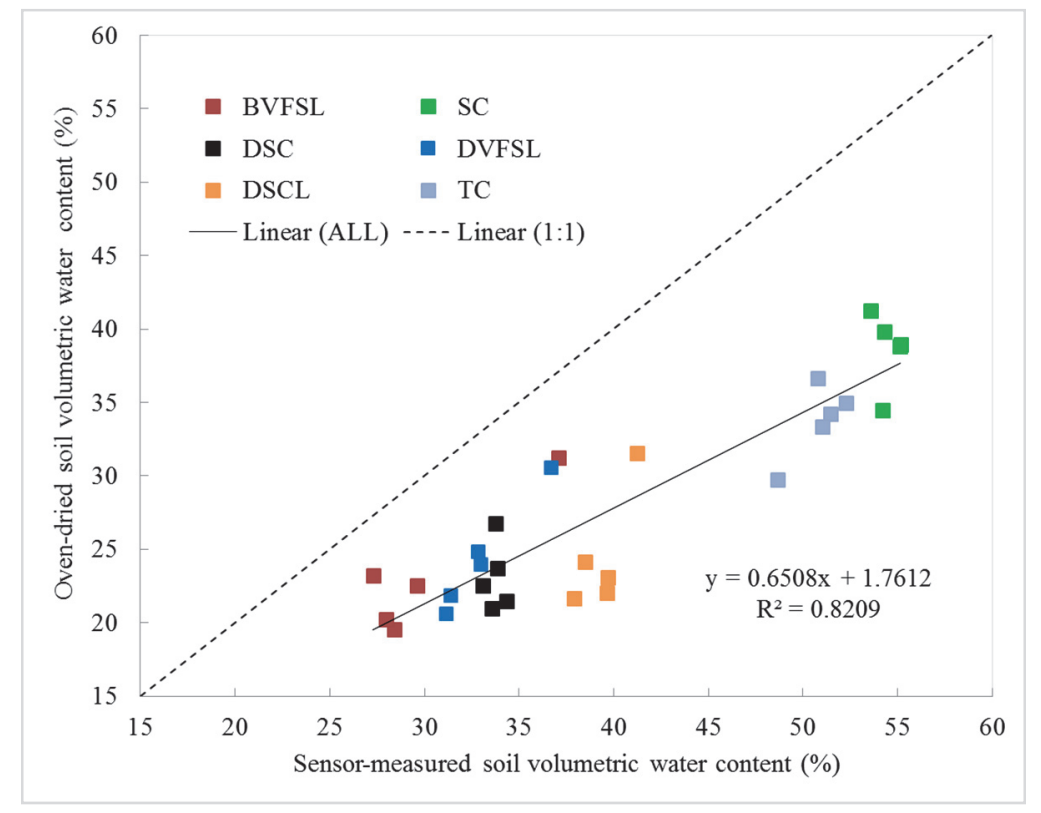

Figure 3. Relationship between sensor-measured SVWC and oven-dried SVWC. 


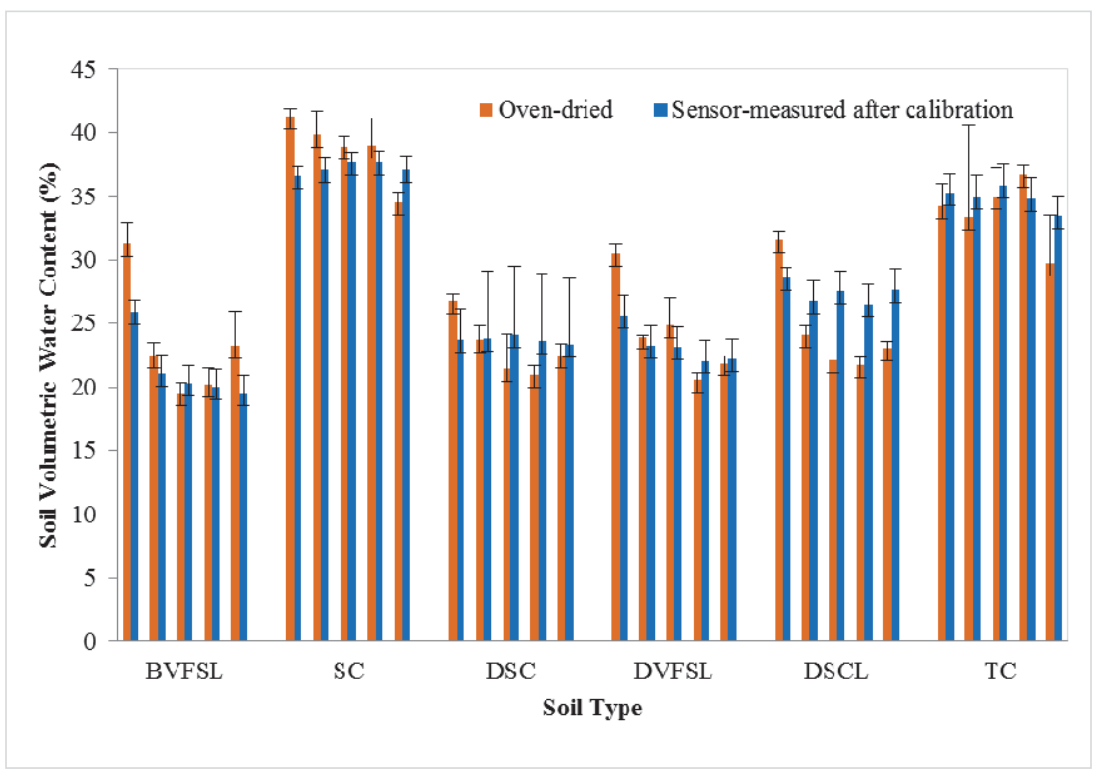

Figure 4. Calibrated sensor-measured SVWC and oven-dried SVWC with standard error bars for Bosket very fine sandy loam (BVFSL), Sharkey clay (SC), Dundee silty clay (DSC), Dundee very fine sandy loam (DVFSL), Dundee silty clay loam (DSCL), and Tunica clay (TC).

Table 2. Average oven-dried soil volumetric water content $(\%)$, calibrated sensor-measured soil volumetric water content (\%), and sensor measurement error $(\%)$ in different soils.

\begin{tabular}{|c|c|c|c|c|c|c|}
\hline Measurement Type & BVFSL & $\mathrm{SC}$ & DSC & DVFSL & DSCL & $\mathrm{TC}$ \\
\hline Oven-dried & 23.35 & 38.67 & 23.08 & 24.35 & 24.5 & 33.78 \\
\hline Sensor-measured & 21.34 & 37.20 & 23.70 & 23.24 & 27.40 & 34.85 \\
\hline Error & -8.6 & -3.8 & 2.7 & -4.5 & 11.8 & 3.2 \\
\hline
\end{tabular}

Table 3. Mean soil volumetric water content (\%) measured by EC-5 and 5TM sensors during the three-month test. Means with same letter under each soil type are not significantly different at the 0.05 level.

\begin{tabular}{|c|c|c|c|c|c|c|}
\hline Sensor & BVFSL & $\mathrm{SC}$ & $\mathrm{DSC}$ & DVFSL & DSCL & $\mathrm{TC}$ \\
\hline EC-5 \#1 & $18.0 \mathrm{c}$ & $36.5 \mathrm{c}$ & $16.7 \mathrm{c}$ & $19.5 \mathrm{~d}$ & $25.3 \mathrm{c}$ & $33.7 \mathrm{~b}$ \\
\hline EC-5 \#2 & $24.5 \mathrm{a}$ & $37.2 \mathrm{~b}$ & $26.4 \mathrm{~b}$ & $27.8 \mathrm{a}$ & $27.9 \mathrm{~b}$ & $36.1 \mathrm{a}$ \\
\hline EC-5 \#3 & $24.2 \mathrm{a}$ & $39.5 \mathrm{a}$ & $29.6 \mathrm{a}$ & $25.5 \mathrm{~b}$ & $32.2 \mathrm{a}$ & $37.6 \mathrm{a}$ \\
\hline $5 \mathrm{TM}$ & $20.0 \mathrm{~b}$ & $35.3 \mathrm{~d}$ & $\mathrm{NA}^{[\mathrm{a}]}$ & $21.7 \mathrm{c}$ & $24.8 \mathrm{~d}$ & $29.1 \mathrm{c}$ \\
\hline
\end{tabular}

[a] The sensor failed during the test.

different from that measured by the EC-5 sensors in all soil types. Performance consistency across the sensors should be taken into consideration in applications of these sensors.

\section{SoIL Water Potential}

Figure 5 compares the SWP measured by the MPS-2 and 200SS sensors in the five soil sampling cycles. In the BVFSL and DVFSL soils, the measurements by these two types of sensors followed each other fairly well. The SWP values measured by the MPS-2 sensors were much higher than those measured by the 200SS sensors for the DSC and DSCL soils. However, for the SC and TC soils, the SWP values measured by the 200SS sensors showed a trend of being higher than those measured by the MPS- 2 sensors. This result indicates that soil type influenced the performance of the sensors. In figure 5, three measurements from the 200SS sensors in the BVFSL, SC, and TC soils were zero because the soil was saturated with water. However, the MPS-2 sensors did not indicate the water saturation of these soils.

The MPS-2 and 200SS sensors both showed their ability to detect trends in SWP values. However, like the SVWC sensors, the outputs of the same model sensors could vary significantly under the same test conditions (tables 4 and 5). For example, as given in table 4, the SWP measured by the
MPS-2 \#1 sensor in the BVFSL soil was consistent with that of the MPS-2 \#3 sensor but significantly different from that of the MPS-2 \#2 sensor. Taking another example in table 5, the SWP measurements by the 200SS \#2 and \#3 sensors in the BVFSL soil agreed well with each other, but they were significantly different from the measurement by the 200SS \#1 sensor. Table 6 provides a comparison between the mean SWP measurements for all MPS-2 sensors and all 200SS sensors. Except for the SC soil, the SWP measured by the MPS-2 sensors was significantly different from that measured by the 200SS sensors for all soil types used in this study. The relative difference was smallest for the DVFSL soil and largest for the DSCL soil.

\section{SOIL TEMPERATURE}

All soil temperature sensors performed very well with all types of soils in the test, with the individual temperature readings from each sensor very close to the mean of all sensor readings. Means of soil temperature measured by the soil temperature sensors during the three-month test are given in table 7. ANOVA indicated that the soil temperatures determined by the sensors in each soil type were not significantly different, except for two observations. One observation was related to the 5TM sensor in the SC soil, in which the tem- 


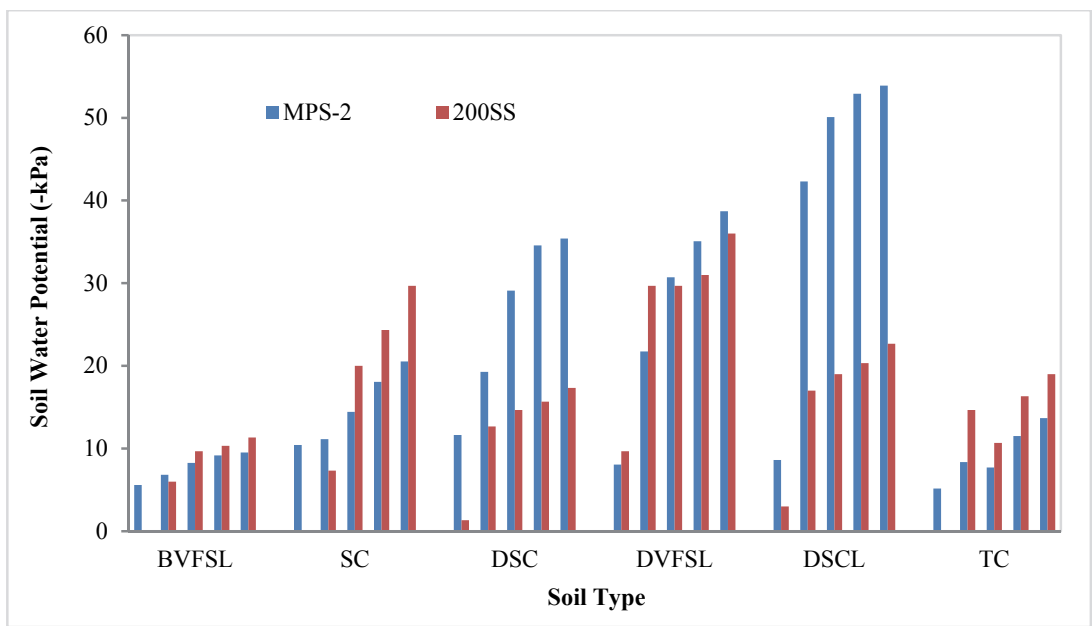

Figure 5. Soil water potential measured by MPS-2 and 200SS sensors with temperature compensation in different soils.

Table 4. Means of soil water potential (-kPa) measured by MPS-2 sensors with temperature compensation during the three-month test. Means with same letter under each soil type are not significantly different at the 0.05 level.

\begin{tabular}{ccccccc}
\hline Sensor & BVFSL & SC & DSC & DVFSL & DSCL & TC \\
\hline MPS-2 \#1 & $7.4 \mathrm{~b}$ & $13.0 \mathrm{~b}$ & $16.9 \mathrm{a}$ & $17.1 \mathrm{a}$ & $34.0 \mathrm{~b}$ & $10.7 \mathrm{~b}$ \\
MPS-2 \#2 & $6.3 \mathrm{a}$ & $12.3 \mathrm{ab}$ & $19.2 \mathrm{a}$ & $17.2 \mathrm{a}$ & $48.6 \mathrm{c}$ & $6.5 \mathrm{a}$ \\
MPS-2 \#3 & $7.4 \mathrm{~b}$ & $11.9 \mathrm{a}$ & $24.9 \mathrm{~b}$ & $29.6 \mathrm{~b}$ & $28.9 \mathrm{a}$ & $5.7 \mathrm{a}$ \\
\hline
\end{tabular}

Table 5. Means of soil water potential (-kPa) measured by 200SS sensors with temperature compensation during the three-month test. Means with same letter under each soil type are not significantly different at the 0.05 level.

\begin{tabular}{ccccccc}
\hline Sensor & BVFSL & SC & DSC & DVFSL & DSCL & TC \\
\hline 200SS \#1 & $3.2 \mathrm{~b}$ & $23.1 \mathrm{a}$ & $8.6 \mathrm{c}$ & $26.9 \mathrm{a}$ & $12.1 \mathrm{c}$ & $8.9 \mathrm{~b}$ \\
$200 S S$ \#2 & $6.4 \mathrm{a}$ & $4.8 \mathrm{~b}$ & $10.8 \mathrm{~b}$ & $22.8 \mathrm{~b}$ & $15.2 \mathrm{~b}$ & $7.7 \mathrm{~b}$ \\
$200 S$ \#3 & $6.1 \mathrm{a}$ & $4.4 \mathrm{~b}$ & $13.9 \mathrm{a}$ & $26.2 \mathrm{a}$ & $17.8 \mathrm{a}$ & $12.9 \mathrm{a}$ \\
\hline
\end{tabular}

Table 6. Means of average soil water potential (-kPa) measured by MPS-2 and 200SS sensors with temperature compensation during the threemonth test. Means with same letter under each soil type are not significantly different at the 0.05 level.

\begin{tabular}{ccccccc}
\hline Sensor & BVFSL & SC & DSC & DVFSL & DSCL & TC \\
\hline MPS-2 average & $7.0 \mathrm{~b}$ & $12.4 \mathrm{a}$ & $20.3 \mathrm{~b}$ & $21.2 \mathrm{a}$ & $37.2 \mathrm{~b}$ & $7.6 \mathrm{a}$ \\
200SS average & $5.3 \mathrm{a}$ & $10.6 \mathrm{a}$ & $11.1 \mathrm{a}$ & $25.0 \mathrm{~b}$ & $14.7 \mathrm{a}$ & $9.8 \mathrm{~b}$ \\
\hline
\end{tabular}

Table 7. Means of soil temperature $\left({ }^{\circ} \mathrm{F}\right)$ measured by different soil temperature sensors during the three-month test. Means with same letter under each soil type are not significantly different at the 0.05 level.

\begin{tabular}{ccccccc}
\hline Sensor & BVFSL & SC & DSC & DVFSL & DSCL & TC \\
\hline MPS-2 \#1 & $75.5 \mathrm{a}$ & $75.7 \mathrm{~b}$ & $76.5 \mathrm{a}$ & $76.5 \mathrm{a}$ & $76.4 \mathrm{a}$ & $75.9 \mathrm{~b}$ \\
MPS-2 \#2 & $75.4 \mathrm{a}$ & $75.9 \mathrm{~b}$ & $76.5 \mathrm{a}$ & $76.5 \mathrm{a}$ & $76.1 \mathrm{a}$ & $78.3 \mathrm{a}$ \\
MPS-2 \#3 & $76.0 \mathrm{a}$ & $75.7 \mathrm{~b}$ & $76.3 \mathrm{a}$ & $76.3 \mathrm{a}$ & $77.1 \mathrm{a}$ & $77.3 \mathrm{ab}$ \\
5TM & $76.0 \mathrm{a}$ & $77.6 \mathrm{a}$ & $77.1 \mathrm{a}$ & $77.1 \mathrm{a}$ & $77.0 \mathrm{a}$ & $78.1 \mathrm{ab}$ \\
200TS & $76.0 \mathrm{a}$ & $75.6 \mathrm{~b}$ & $75.8 \mathrm{a}$ & $75.8 \mathrm{a}$ & $76.0 \mathrm{a}$ & $78.1 \mathrm{a}$ \\
\hline
\end{tabular}

perature measured by the 5TM was slightly higher than that measured by the other sensors. The other observation involved the MPS-2 \#1 sensor in the TC soil, in which this sensor's measurement was about $2.5 \%$ lower than that of the other sensors (table 7). Soil temperature varied during the testing period, and the measurements from all sensors followed the same trend and agreed well (fig. 6). The average soil temperature in the different soil types was about the same in this study. Due to variations in the readings among the same sensor type and among different sensor types, the sensors should be calibrated individually and by soil type to obtain the most accurate readings.

\section{Practical Use of Soil Moisture Sensors}

Previous studies have indicated that soil moisture sensors were able to detect the trends and variability of soil moisture and could be used as a tool for irrigation scheduling. How- ever, procedures for proper installation, calibration, and maintenance of soil moisture sensors are critical for the success of sensor-based irrigation scheduling. We suggest installing the soil moisture sensors in the predominant soil of the field at multiple depths, such as 15,30 , and $61 \mathrm{~cm}$, across the crop root zone. In sensor installation, the sensors are inserted horizontally into the soil with minimum disturbance of the soil, and the sensor prongs must have good contact with the soil. For better understanding and proper use of the sensor measurements, the sensors need to be calibrated with the specific soils that they are intended to measure. The calibration can be performed using the gravimetric method or with an instrument that can provide accurate soil moisture measurement. Considering the sensor cost, reliability, and the variability of individual sensors, we recommend selecting two places in one field to install sensors for monitoring soil moisture in sensor-based irrigation scheduling. 


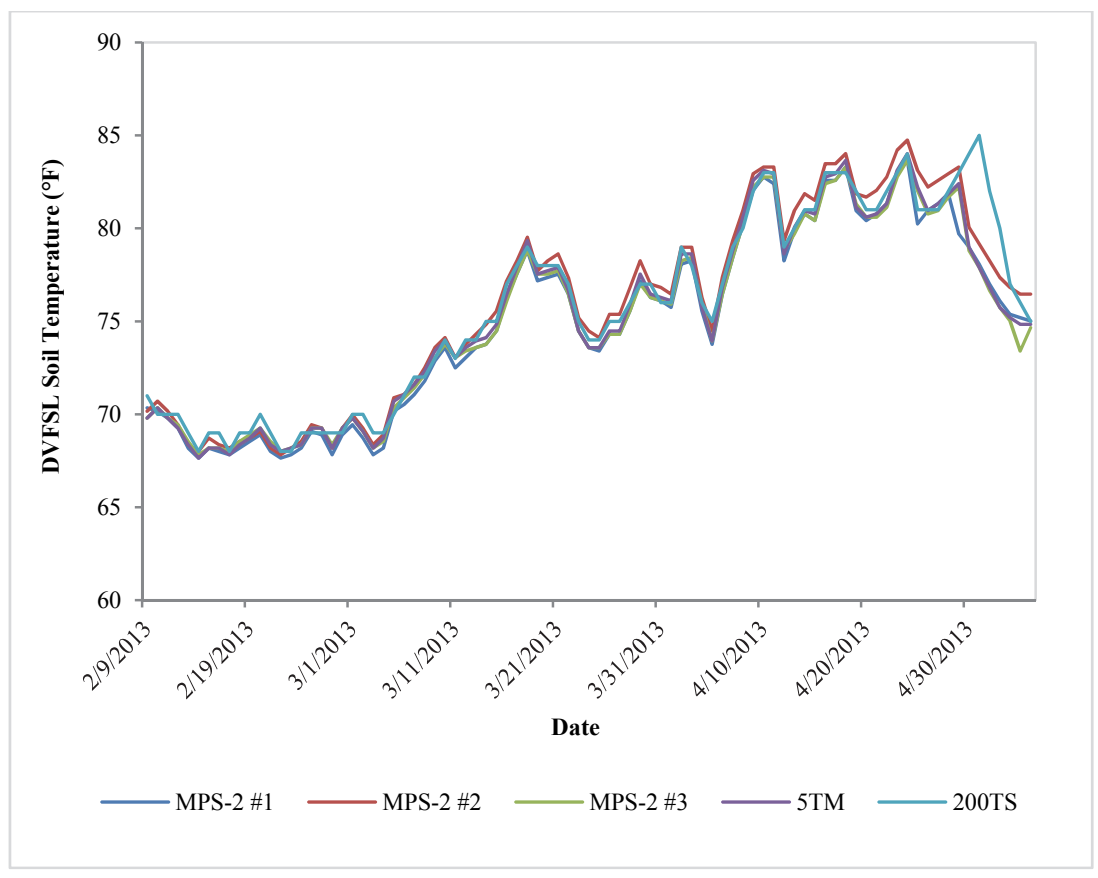

Figure 6. DVFSL soil temperature determined using different sensors.

\section{CONCLUSIONS}

The EC-5 and 5TM SVWC sensors, the MPS-2 and 200SS SWP sensors, and the 200TS soil temperature sensors were evaluated in six Mississippi Delta soils. Volumetric water contents of the soils were determined using the ovendrying method. Oven-dried volumetric water contents were compared with the sensor measurements, and their relationship was used to calibrate the SVWC sensor measurements. Results indicated that readings from the EC-5 and 5TM sensors had a linear regression relationship with oven-dried SVWC $\left(r^{2}=0.82\right)$. The MPS-2 and 200SS sensors were compared against each other. In general, the soil moisture sensors could detect the trends in soil moisture for irrigation scheduling. However, the accuracy of sensor measurements varied significantly between different sensor models and among sensors of the same model. To obtain accurate absolute measurements, soil moisture sensors should be calibrated individually with specific soils. Soil temperature measurements could be obtained consistently using the 5TM, MPS-2, and 200TS sensors.

\section{ACKNOWLEDGEMENTS}

The authors extend their thanks to Mr. Jonnie Baggard, Joseph DeAngelo, and Richard Horton for their assistance in this study. This project was partially supported by Cotton Incorporated (Cary, N.C.). Mention of commercial products is solely for the purpose of providing specific information and should not be construed as a product endorsement by the authors nor by the institutions with which the authors are affiliated.

\section{REFERENCES}

Basinger, J. M., Kluitenberg, G. J., Ham, J. M., Frank, J. M., Barnes, P. L., \& Kirkham, M. B. (2003). Laboratory evaluation of the dual-probe heat pulse method for measuring soil water content. Vadose Zone J., 2(3), 389-399. https://doi.org/10.2136/vzj2003.3890

Chanzy, A., Chadoeuf, J., Gaudu, J. C., Mohrath, D., Richard, G., \& Bruckler, L. (1998). Soil moisture monitoring at the field scale using automatic capacitance probes. European J. Soil Sci., 49(4), 637-648. https://doi.org/10.1046/j.13652389.1998.4940637.x

Cox, M. S., Gerard, P. D., \& Abshire, M. J. (2006). Selected soil properties' variability and their relationships with yield in three Mississippi fields. Soil Sci., 171(7), 541-551. https://doi.org/10.1097/01.ss.0000228031.49776.0f

Decagon. (2010a). 5TM water content and temperature sensors: Operator's manual. Pullman, WA: Decagon Devices. Retrieved from http://www.agrolan.co.il/UploadProductFiles/Manual-5TM.pdf Decagon. (2010b). EC-20, EC-10, and EC-5 soil moisture sensors: User's manual. Pullman, WA: Decagon Devices. Retrieved from

http://manuals.decagon.com/Retired\%20and\%20Discontinued/ Manuals/EC-20-EC-10-EC-5-Soil-Moisture-Sensor-OperatorsManual-(discontinued).pdf

Decagon. (2017). MPS-2 and MPS-6 dielectric water potential sensors: Operator's manual. Pullman, WA: Decagon Devices. Retrieved from

http://manuals.decagon.com/Retired\%20and\%20Discontinued/ Manuals/13755_MPS-2and6_Web.pdf

Dukes, M. D., \& Scholberg, J. M. (2005). Soil moisture controlled subsurface drip irrigation on sandy soils. Appl. Eng. Agric., 21(1), 89-101. https://doi.org/10.13031/2013.17916

Evett, S. R., \& Parkin, G. W. (2005). Advances in soil water content sensing: The continuing maturation of technology and theory. Vadose Zone J., 4(4), 986-991. https://doi.org/10.2136/vzj2005.0099

Evett, S. R., Tolk, J. A., \& Howell, T. A. (2006). Soil profile water content determination: Sensor accuracy, axial response, calibration, temperature dependence, and precision . Vadose Zone J., 5(3), 894-907. https://doi.org/10.2136/vzj2005.0149

Fares, A., \& Alva, A. K. (2000). Evaluation of capacitance probes for optimal irrigation of citrus through soil moisture 
monitoring in an entisol profile. Irrig. Sci., 19(2), 57-64. https://doi.org/10.1007/s002710050001

Irrometer. (2018). Watermark soil moisture senor: Model 200SS Riverside, CA: Irrometer Co. Retrieved from http://www.irrometer.com/pdf/sensors/403\%20WATERMAR K\%20Sensor-WEB.pdf

Leib, B. G., Jabro, J. D., \& Matthews, G. R. (2003). Field evaluation and performance comparison of soil moisture sensors. Soil Sci., 168(6), 396-408. https://doi.org/10.1097/01.ss.0000075285.87447.86

Miranda, F. R., Yoder, R. E., Wilkerson, J. B., \& Odhiambo, L. O. (2005). An autonomous controller for site-specific management of fixed irrigation systems. Comput. Electron. Agric., 48(3), 183-197. https://doi.org/10.1016/j.compag.2005.04.003

Mittelbach, H., Lehner, I., \& Seneviratne, S. I. (2012). Comparison of four soil moisture sensor types under field conditions in Switzerland. J. Hydrol., 430-431, 39-49. https://doi.org/10.1016/j.jhydrol.2012.01.041

Seyfried, M. S., \& Murdock, M. D. (2001). Response of a new soil water sensor to variable soil, water content, and temperature. SSSA J., 65(1), 28-34. https://doi.org/10.2136/sssaj2001.65128x

Seyfried, M. S., \& Murdock, M. D. (2004). Measurement of soil water content with a $50 \mathrm{MHz}$ soil dielectric sensor. SSSA J., 68(2), 394-403. https://doi.org/10.2136/sssaj2004.3940
Susha Lekshmi S. U., Singh, D. N., \& Baghini, M. S. (2014). A critical review of soil moisture measurement. Measurement, $54,92-105$.

https://doi.org/10.1016/j.measurement.2014.04.007

Thomasson, J. A., Sui, R., Cox, M. S., \& Al-Rajehy, A. (2001). Soil reflectance sensing for determining soil properties in precision agriculture. Trans. ASAE, 44(6), 1445-1453. https://doi.org/10.13031/2013.7002

Thomson, S. J., \& Armstrong, F. (1987). Calibration of the Watermark model 200 soil moisture sensor. Appl. Eng. Agric., 3(2), 186-189. https://doi.org/10.13031/2013.26670

Vaz, C. M. P., Jones, S., Meding, M., \& Tuller, M. (2013). Evaluation of standard calibration functions for eight electromagnetic soil moisture sensors. Vadose Zone J., 12(2). https://doi.org/10.2136/vzj2012.0160

Vellidis, G., Tucker, M., Perry, C., Kvien, C., \& Bednarz, C. (2008). A real-time wireless smart sensor array for scheduling irrigation. Comput. Electron. Agric., 61(1), 44-50. https://doi.org/10.1016/j.compag.2007.05.009

Yao, T., Wierenga, P. J., Graham, A. R., \& Neuman, S. P. (2004). Neutron probe calibration in a vertically stratified vadose zone. Vadose Zone J,, 3(4), 1400-1406. https://doi.org/10.2136/vzj2004.1400

Yoder, R. E., Johnson, D. L., Wilkerson, J. B., \& Yoder, D. C. (1997). Soilwater sensor performance. Appl. Eng. Agric., 14(2), 121-133. https://doi.org/10.13031/2013.19373 